\title{
QUEEN'S
UNIVERSITY
BELFAST
}

\section{Prevalence of Refractive Error, Presbyopia, and Spectacle Coverage in Bogotá, Colombia: A Rapid Assessment of Refractive Error}

Casas Luque, L., Naidoo, K., Chan, V. F., Silva, J. C., Naduvilath, T. J., Peña, F., Mayorga, M., \& Ramírez, L. (2019). Prevalence of Refractive Error, Presbyopia, and Spectacle Coverage in Bogotá, Colombia: A Rapid Assessment of Refractive Error. Optometry and vision science : official publication of the American Academy of Optometry, 96(8), 579-586. https://doi.org/10.1097/OPX.0000000000001409

Published in:

Optometry and vision science : official publication of the American Academy of Optometry

Document Version:

Peer reviewed version

Queen's University Belfast - Research Portal:

Link to publication record in Queen's University Belfast Research Portal

Publisher rights

(c) 2019 American Academy of Optometry. This work is made available online in accordance with the publisher's policies. Please refer to any applicable terms of use of the publisher.

\section{General rights}

Copyright for the publications made accessible via the Queen's University Belfast Research Portal is retained by the author(s) and / or other copyright owners and it is a condition of accessing these publications that users recognise and abide by the legal requirements associated with these rights.

Take down policy

The Research Portal is Queen's institutional repository that provides access to Queen's research output. Every effort has been made to ensure that content in the Research Portal does not infringe any person's rights, or applicable UK laws. If you discover content in the Research Portal that you believe breaches copyright or violates any law, please contact openaccess@qub.ac.uk. 


\title{
Prevalence of Refractive Error, Presbyopia, and Spectacle Coverage in Bogotá, Colombia: A Rapid Assessment of Refractive Error
}

\author{
Luisa Casas Luque, OD, ${ }^{1 *}$ Kovin Naidoo, PhD, OD, FAAO, ${ }^{2}$ Ving Fai Chan, PhD, OD, ${ }^{3}$ Juan Carlos Silva, MD, ${ }^{4}$ \\ Thomas John Naduvilath, PhD, ${ }^{5}$ Fernando Peña, MD, ${ }^{6}$ Myriam Mayorga, MSc, OD, ${ }^{7}$ and Leonardo Ramírez, $\mathrm{OD}^{1}$
}

\begin{abstract}
SIGNIFICANCE: Uncorrected refractive error is the leading cause of visual impairment; therefore, reducing its prevalence is important worldwide. For two decades, there has not been a comprehensive assessment of refractive error in Latin America.

PURPOSE: The purpose of this study was to determine the current prevalence of refractive error, presbyopia, spectacle coverage, barriers to uptake refractive services, and spectacle correction in people 15 years and older in Bogotá, Colombia.

METHODS: A cross-sectional community-based survey was conducted using 50 randomly selected clusters from 10 districts of Bogotá reflecting the socioeconomic status of the city. Respondents 15 years and older were interviewed and underwent standardized clinical eye examinations. Prevalence of uncorrected refractive error, spectacle coverage, and visual impairment were standardized to 2015 age-sex population distribution of Bogotá and further analyzed.

RESULTS: A total of 2886 subjects ( $90 \%$ of 3206 eligible subjects) participated in the study; $39.1 \%$ were male and $60.9 \%$ were female in the age range of 15 to 96 years, with a median age of 46 years (interquartile range, 45 to 54 years). Age- and sex-standardized prevalence of visual impairment was 19.3\% (95\% confidence interval [Cl], 17.8 to $20.8 \%$ ). Prevalence of uncorrected refractive error was $12.5 \%(95 \% \mathrm{Cl}, 11.3$ to $13.7 \%)$. Prevalence of presbyopia among participants 35 years and older was $55.2 \%(95 \% \mathrm{Cl}, 52.9$ to $57.4 \%)$. Spectacle coverage was $50.9 \%$ for distance vision, and it was $33.9 \%$ for presbyopia. Main barrier to spectacle uptake was a limitation in affording spectacles because of economic factors (29.5\%).

CONCLUSIONS: This study provides a current estimate of refractive error using the Rapid Assessment of Refractive Error for Colombia and the Latin American region. The prevalence of uncorrected refractive error and presbyopia was high, and the barriers to spectacle uptake were higher in the lowest socioeconomic strata. The results obtained in the present study will help in making evidence-based decisions related to eye care service delivery in Colombia.
\end{abstract}

Optom Vis Sci 2019;00:00-00. doi:10.1097/OPX.0000000000001409

Copyright ( $\odot 2019$ American Academy of Optometry

Supplemental Digital Content: Direct URL links are provided within the text.

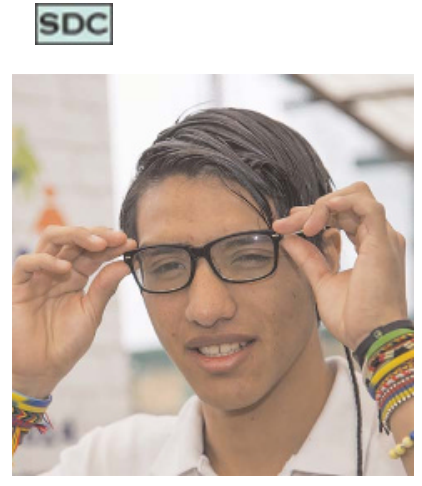
Author Affiliations:
${ }^{1}$ Brien Holden Vision Institute
Foundation, Bogotá, Colombia
${ }^{2}$ African Vision Research Institute,
UKZN, Durban, South Africa
${ }^{3}$ Queen's University of Belfast, Dublin, United Kingdom
${ }^{4}$ Pan-American Health Organization,
Bogotá, Colombia
${ }^{5}$ Brien Holden Vision Institute
Foundation, Sydney, Australia
${ }^{6}$ El Bosque University, Bogotá, Colombia
${ }^{7}$ La Salle University, Bogotá, Colombia
*I.casasluque@brienholdenvision.org

Visual impairment is a global public health challenge that is largely avoidable. ${ }^{1-3}$ Uncorrected refractive error is the leading cause of visual impairment, presenting as a significant burden worldwide. Therefore, reducing the prevalence of uncorrected refractive error is one of the key strategies to achieving the goals of VISION 2020, an international initiative for the elimination of avoidable blindness proposed by the World Health Organization and the International Agency for the Prevention of Blindness in 1999. ${ }^{2,4}$ By nature of its definition, uncorrected refractive error can be addressed simply by an eye examination and the provision of a pair of appropriate spectacles. ${ }^{5,6}$ The burden of refractive error is significant in developing countries because of factors such as low socioeconomic status and inadequate health care infrastructure ${ }^{7-9}$ and the inability to access adequate eye care. ${ }^{10,11}$ Such barriers are even more evident in the remotest areas of low-income countries. ${ }^{12}$

Despite the international focus on reducing the burden of uncorrected refractive error and nine rapid assessments of cataract surgical services or avoidable blindness conducted in the Latin
America and the Caribbean region, ${ }^{13,14}$ there have been no epidemiological surveys of the burden of refractive error conducted in the region. In its most recent strategic plan, the Pan-American Health Organization emphasizes the need to (i) focus on refractive error as a core contributor to visual impairment and (ii) generate evidence to inform planning. ${ }^{15}$ Rapid Assessment of Refractive Error is a population-based survey designed to quickly and accurately determine the prevalence of uncorrected refractive error using a simplified visual acuity $\log M A R$ chart consisting of two lines of optotypes (20/200 and 20/40). 3,5 The Rapid Assessment of Refractive Error overcomes the challenge of large-scale populationbased studies that are costly in time and resources. This approach has been successfully implemented in Eritrea, Tanzania, Uganda, India, and South Africa to determine the prevalence of uncorrected refractive error. ${ }^{16,17}$ If the global target of reducing avoidable visual impairment by $25 \%$ is to be achieved, ${ }^{2,4}$ it is important to understand the magnitude of the problem in each region and hence the need to determine uncorrected refractive error in the Latin 
American region. ${ }^{18}$ Such data will help inform priorities for eye care programs and provide baseline data for future assessments for service impact.

Colombia is the third most populous country in Latin America with an estimated population of $48,203,405$, with $75 \%$ in urban settings. According to population projections of the Colombian National Administrative Department of Statistics, the population of the capital, Bogotá, reached 7,674,366 inhabitants in 2013, representing $16.3 \%$ of the total population of Colombia. ${ }^{19}$ Bogotá also features many rapidly growing urban slums and informal settlements where many displaced persons reside and experience limited access to public services, education, and housing conditions according to the living conditions index, which assesses access to high-quality public services. ${ }^{19}$

Despite the importance of early intervention in detecting and correcting visual impairment for adult population (population $>15$ years old), ${ }^{4,6,10}$ there is still limited information on the burden of uncorrected refractive error in Latin America and the Caribbean. These data are needed to inform appropriate advocacy messages and to plan eye health services and interventions. This study was conducted to determine the prevalence of uncorrected refractive error and spectacle coverage among adults 15 years and older, as well as the prevalence of presbyopia and spectacle coverage among adults 35 years and older. In addition, we sought to determine the barriers to uptake of refractive services and spectacle correction. Progressing our understanding of the magnitude of uncorrected refractive error in Latin American and the Caribbean will offer opportunities to inform priorities for eye care programs and provide baseline data for future assessments of service impact.

\section{METHODS}

Ethics approval was obtained from the ethics committee at $\mathrm{La}$ Salle University in Bogotá, Colombia. All participants gave signed consent in agreement with the tenets of the Declaration of Helsinki.

Previously published studies reported uncorrected refractive error prevalence rates of 6 and $18 \% .^{20-27}$ Using an anticipated estimate prevalence of $12 \%$, with $2 \%$ precision, and a cluster design effect of 2, we determined that a sample size of 2498 was required with $95 \%$ confidence interval. The cluster design effect measures the increased variance using a cluster sampling design compared with a simple random sample and can be considered as a multiplier of the sample size when a cluster design is used. A design effect of 2 is justified given that the clustering was at the household level, resulting in small cluster sizes. Based on an expected response rate of $80 \%$ and a finite population correction for ages $>15$ years, the final sample size was 3206 subjects. Furthermore, the sample was selected proportionate to the sociodemographic group in Bogotá. It is estimated that approximately 40 to $50 \%$ of the population falls into low strata ( 1 and 2 ) and 30 to $40 \%$ falls into middle strata (3 and 4), with the remaining 10 to $20 \%$ falling into high-category (5 and 6) socioeconomic strata. ${ }^{19}$ To determine the prevalence of presbyopia, we included only individuals 35 years and older.

Based on socioeconomic status and the population within each district, 10 districts were randomly selected. To ensure an equal proportion of people from the six socioeconomic strata, from each of these 10 districts, 25 neighborhoods were selected from low socioeconomic strata, 20 from middle socioeconomic strata, and 5 from high socioeconomic strata. Using digital and physical maps from Bogotá, from the central place of the neighborhood, the area was divided into four quadrants, and then a random selection of axes across the blocks of the neighborhoods was made. Starting from the neighborhood center, every fifth house or apartment was visited. At a household level, all individuals 15 years and older were surveyed (Appendix, available at http://links.Iww.com/OPX/A407) and enrolled if they had been living at that house for a minimum period of 6 months and if willing to participate. This process was repeated until the required number of 64 people per cluster was met.

Participants were identified at the household level and then referred to nearby examination location, with appropriate illumination and space for the eye examination. After the recommendations of a report from the World Health Organization in $2001^{28}$ and the standardized Rapid Assessment of Refractive Error methodology conducted in India, ${ }^{29}$ Eritrea, ${ }^{16}$ Uganda, ${ }^{17}$ and Tanzania, ${ }^{5}$ a modified logMAR chart with tumbling E optotypes at 20/40 and 20/200 levels of visual acuity designed for $3 \mathrm{~m}$ was used for distance vision assessment. Distance uncorrected visual acuity was measured monocularly at $3 \mathrm{~m}$ starting with the right eye at the 20/40 line. The same measurements were made with those participants wearing spectacles. If the subject could see four of five optotypes, he or she was considered to have no visual impairment. A subject was considered to have refractive error if distance visual acuity was worse than 20/40 but improved to 20/40 with pinhole. Near vision assessment was conducted binocularly at $40 \mathrm{~cm}$ using a modified logMAR chart with tumbling $\mathrm{E}$ optotypes at 20/40 and 20/80 levels in patients 35 years and older as indicated by the Rapid Assessment of Refractive Error standardized methodology. 3,5,29 Patients unable to see the 20/40 level and whose distance visual acuity was $\geq 20 / 40$ were classified as presbyopic and had an addition prescribed appropriate for their age after a full refraction examination. The anterior segment and fundus were evaluated with direct ophthalmoscopy in all the participants. Once the Rapid Assessment of Refractive Error procedures were completed and data for the study were collected, a full refraction examination was offered for those who did not have improved visual acuity with pinhole. Those with ocular alterations were referred for further ophthalmologic examination. Spectacles were prescribed for distance or near vision depending on the prescription required. Those who had uncorrected refractive error and/or uncorrected presbyopia were then asked the reasons why they did not seek management before. This was done using a questionnaire with closed-ended questions where the participants could choose a maximum of three reasons. Individuals who were unwilling to undergo the examination were excluded.

\section{Data Analysis and Management}

Data were tabulated as frequency and percentages. Prevalence data were standardized to 2015 age-sex population distribution of Bogotá. Logistic regression was used to analyze the odds of uncorrected refractive error, visual impairment, and presbyopia associated with demographic factors, namely, age, sex, occupation, education, and socioeconomic status. Statistical significance was set at $5 \%$.

\section{Definitions}

1. Visual impairment was defined as presenting distance visual acuity worse than 20/40.

2. Uncorrected refractive error was defined as presenting distance visual acuity $<20 / 40$ but correctable to $\geq 20 / 40$ using a pinhole.

3. Monocular data were converted to binocular rates based on better-eye data.

4. Presbyopia was defined as participants 35 years and older with binocular near visual acuity $<20 / 40$ at $40 \mathrm{~cm}$ whose 
distance visual acuity was at least 20/40 with pinhole or correction.

5. Distance spectacle coverage was calculated using the following formula: [met need/(met need + unmet need)] $\times$ $100 \%$. "Met need" was defined as the number of subjects with spectacles having binocular unaided visual acuity $<20 / 40$ but improved to, or were better than, 20/40. "Unmet need" was defined as the number of subjects without spectacles whose distance visual acuity was $<20 / 40$ but improved to $20 / 40$ or better with correction.

6. Near spectacle coverage was calculated using the following formula: [met need/(met need + unmet need)] $\times 100 \%$. "Met need" was defined as the number of spectacle-wearing subjects having binocular unaided visual acuity $<20 / 40$ but improved to, or became better than, 20/40 with near correction. "Unmet need" was defined as the number of subjects without spectacles whose near visual acuity was $<20 / 40$ but improved to $20 / 40$ or better with near correction.

\section{RESULTS}

A total of 2886 subjects ( $90 \%$ of 3206 subjects eligible) from 50 neighborhoods in 10 different districts participated in the study, with $39.1 \%$ being male and $60.9 \%$ being female. The median age of participants was 46 years (interquartile range, 45 to 54 years; Table 1). The district with the highest participation was Kennedy (socioeconomic strata 3 and $4 ; 13.1 \%$ of the sample [ $n=377]$ ), whereas Usaquen was the district with lowest participation (socioeconomic strata 5 and $6 ; 4.5 \%$ of the sample $[n=129]$ ). Thirty-two percent of the subjects in the sample had completed secondary education, $11.2 \%$ were undergraduate, and only $1.1 \%$ reached the postgraduate level. Most of the sample were engaged in home duties (29.2\%), followed by people who were employed (25.3\%) and consultants (22\%).

\section{Visual Impairment}

The level of $20 / 40$ or better presenting visual acuity was $80.7 \%$, followed by a total visual impairment of $19.3 \%$ (95\% confidence interval, 17.8 to $20.8 \%$; Table 2). The highest prevalence of visual impairment was found in the districts of Bosa and Usme (socioeconomic strata 1 and 2) at 27.2 and $25.8 \%$, respectively, whereas the lowest prevalence of visual impairment (14.1\%) was found in Usaquen district conforming to socioeconomic strata 5 and $6(P=.001)$. Multivariable logistic regression analysis revealed that participants 65 years and older had a significantly higher likelihood of being visually impaired $(P<.001)$. Participants with no formal schooling had the highest likelihood (odds ratio, 6.05; $95 \%$ confidence interval, 3.44 to 10.62 ) of presenting visual impairment, as well as those who lived in low socioeconomic strata (odds ratio, 1.82; 95\% confidence interval, 1.09 to 3.04). A detailed breakdown of the odds ratio analysis for visual impairment is provided in Table 3.

\section{Uncorrected Refractive Error}

The age- and sex-standardized prevalence of uncorrected refractive error was $12.5 \%$ (95\% confidence interval, 11.3 to $13.7 \%$ ). Uncorrected refractive error was highest in the 70- to 79-year age group and significantly different between age groups $(P=.002$; Fig. 1). The age- and sex-standardized prevalence of uncorrected
TABLE 1. Demographic profile of the participants

\begin{tabular}{|c|c|c|}
\hline \multirow[b]{2}{*}{ Variable } & \multicolumn{2}{|c|}{ Participants } \\
\hline & n & $\%$ \\
\hline \multicolumn{3}{|l|}{ Age group (y) } \\
\hline$\leq 24$ & 511 & 17.7 \\
\hline $25-34$ & 386 & 13.4 \\
\hline $35-44$ & 369 & 12.8 \\
\hline $45-54$ & 590 & 20.4 \\
\hline $55-64$ & 535 & 18.5 \\
\hline $65-74$ & 299 & 10.4 \\
\hline$\geq 75$ & 196 & 6.8 \\
\hline \multicolumn{3}{|l|}{ Sex } \\
\hline Male & 1129 & 39.1 \\
\hline Female & 1757 & 60.9 \\
\hline \multicolumn{3}{|l|}{ Education } \\
\hline No formal schooling & 70 & 2.4 \\
\hline Primary school incomplete & 284 & 9.8 \\
\hline Primary school complete & 451 & 15.6 \\
\hline Secondary school incomplete & 537 & 18.6 \\
\hline Secondary school complete & 912 & 31.6 \\
\hline University student & 260 & 9.0 \\
\hline Graduate & 322 & 11.2 \\
\hline Post-graduate & 32 & 1.1 \\
\hline Do not know & 14 & 0.5 \\
\hline No response & 4 & 0.1 \\
\hline \multicolumn{3}{|l|}{ Occupation } \\
\hline Professional & 41 & 1.4 \\
\hline Consultant & 635 & 22.0 \\
\hline Informal job & 54 & 1.9 \\
\hline Employed & 730 & 25.3 \\
\hline Home duties & 841 & 29.1 \\
\hline Student & 295 & 10.2 \\
\hline Retired & 135 & 4.7 \\
\hline Unemployed & 141 & 4.9 \\
\hline Others & 9 & 0.3 \\
\hline No response & 5 & 0.2 \\
\hline
\end{tabular}

refractive error was $13.2 \%$ in female subjects versus $11.3 \%$ in male subjects $(P=.13)$. Multivariable logistic regression analysis revealed that the risk of uncorrected refractive error was significantly lower in the middle-aged groups (45- to 54-year age group; odds ratio, 0.66; $95 \%$ confidence interval, 0.46 to 0.96 ). The risk of uncorrected refractive error was also observed to be higher in those with low educational levels, with statistical significance achieved for those with primary-level education compared with those with graduate-level education $(P=.004)$. Uncorrected refractive error was higher in subjects who performed an informal job (occasional working activity performed without a legal contract) as their occupation (18.9\%) compared with professionals (4.9\%), although this did not achieve statistical significance (odds ratio, 4.5; 95\% confidence interval, 
TABLE 2. Visual impairment distribution (95\% Cl, 17.8-20.8\%)

\begin{tabular}{|c|c|c|c|}
\hline \multirow[b]{2}{*}{ Visual impairment } & \multirow[b]{2}{*}{ Visual acuity } & \multicolumn{2}{|c|}{ Standardized presenting vision best eye } \\
\hline & & No. & $\%$ \\
\hline No impairment & $\geq 20 / 40$ & 2321 & 80.7 \\
\hline \multirow[t]{2}{*}{ Severe visual impairment } & $<20 / 200-20 / 400$ & 43 & 1.5 \\
\hline & $<20 / 400-20 / 1200$ & 8 & 0.3 \\
\hline Blindness & No light perception & 0 & 0 \\
\hline Total visual impairment $(n=2877)$ & & 556 & 19.3 \\
\hline
\end{tabular}

$\mathrm{Cl}=$ confidence interval .

TABLE 3. A detailed breakdown of the odds ratio analysis for visual impairment

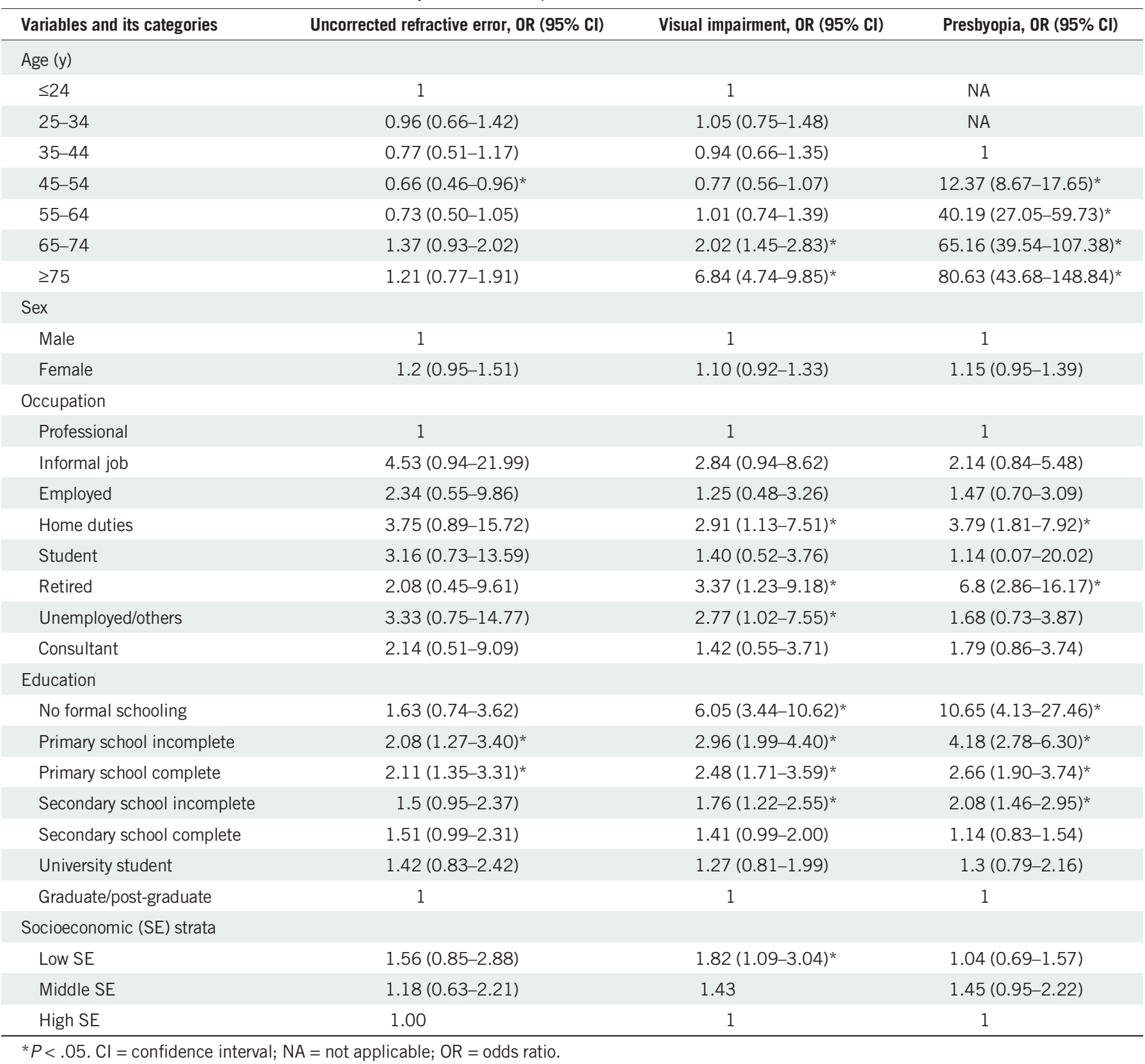




\section{Uncorrected Refractive Error and Presbyopia by Age}

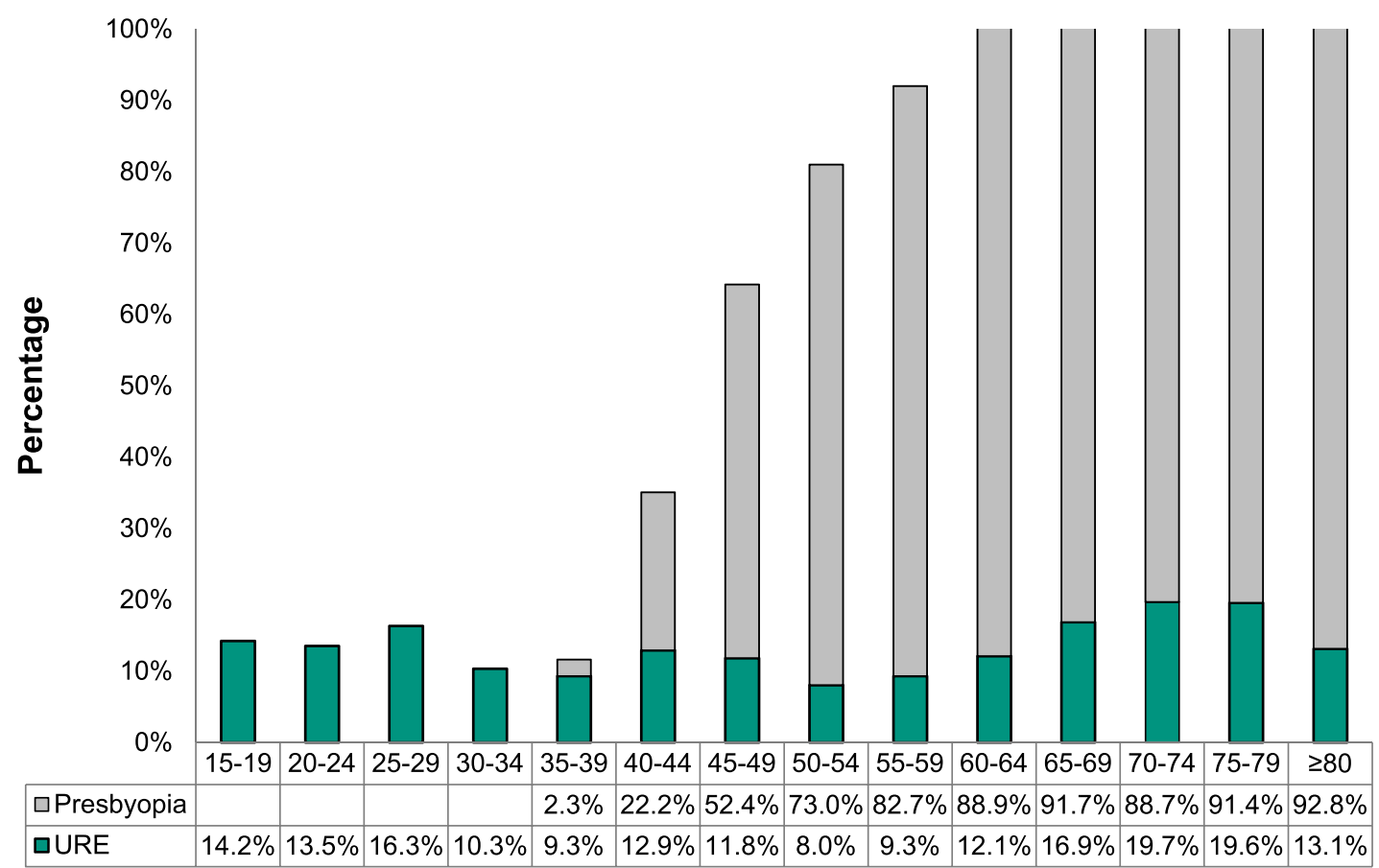

FIGURE 1. Age-standardized uncorrected refractive error and presbyopia distribution.

0.9 to 21.9 ) in the multivariate analysis. A detailed breakdown of the odds ratio analysis for uncorrected refractive error is provided in Table 3.

\section{Presbyopia}

Age- and sex-standardized prevalence of presbyopia was $55.2 \%$ (95\% confidence interval, 52.9 to $57.4 \%$ ), and prevalence was higher in subjects 80 years and older (Fig. 1). There was no significant difference in prevalence of presbyopia between sexes. Multivariable logistic regression analysis revealed that the odds of presenting with presbyopia increased significantly with age $(P<.001)$. Uncorrected presbyopia increased significantly with decreasing levels of education. Unmet near vision needs increased for those who did not complete secondary level (odds ratio, 2.08; 95\% confidence interval, 1.46 to 2.95 ) and for those who had no formal education (odds ratio, 10.65; 95\% confidence interval, 4.13 to 27.46 ) compared with graduates. In terms of occupations, those who retired (odds ratio, $6.8 ; 95 \%$ confidence interval, 2.9 to 16.2 ) and those with home duties (odds ratio, $3.8 ; 95 \%$ confidence interval, 1.8 to 7.9 ) had a significantly higher risk of presenting uncorrected presbyopia compared with professionals. A detailed breakdown of the odds ratio analysis for presbyopia is provided in Table 3.

\section{Spectacle Coverage}

Spectacle coverage was $50.9 \%$ for distance vision (met need [288]/unmet need [278] + met need [288]), and spectacle coverage for near vision was 33.9\% (met need [468]/[unmet need [911] + met need [468]). Single-vision spectacles were the most common form of spectacle correction (58.4\%) followed by multifocals (35.7\%). When analyzed by socioeconomic strata, spectacle coverage was observed to increase with the increase in socioeconomic status for both distance and near vision (Fig. 2).

\section{Barriers and Accessibility}

For those participants who had never worn spectacles, barriers were elicited by means of questionnaire. Barriers were present only in the low and middle socioeconomic strata, and the most frequently reported was the limitation in affording spectacles because of economic factors (29.5\%) being higher in the low socioeconomic strata, followed by the limitations in affording the cost of an eye examination $(17.0 \%)$, lack of need of requiring a consultation by the patients (15.9\%), and lack of awareness of the problem (13.6\%; Fig. 3). There were no barriers reported by participants of the high socioeconomic strata.

\section{DISCUSSION}

To our knowledge, this is the first rapid assessment of refractive error conducted in Latin America and in a heavily populated capital city such as Bogotá. Although efforts have been undertaken in Colombia previously to measure refractive error, ${ }^{14,22}$ there have been no studies using an internationally validated methodology with a randomized sample to enable generalization of results, nor was there any that has included a population-based survey. The age- and sex-standardized prevalence of uncorrected refractive error was $12.5 \%$, which is higher than the uncorrected refractive error prevalence reported in the Rapid Assessment of Refractive Error studies completed in other regions of the world such as South India (5.5\%) and Eritrea (6.4\%), where the population size ranges from 635,836 to $1,318,110$ inhabitants and has a combination of rural and urban socioeconomic demographics. ${ }^{16,29}$

Age- and sex-standardized prevalence of visual impairment in the study was found to be $19.3 \%$. The highest visual impairment was found in Bosa and Usme districts, both of which are within 


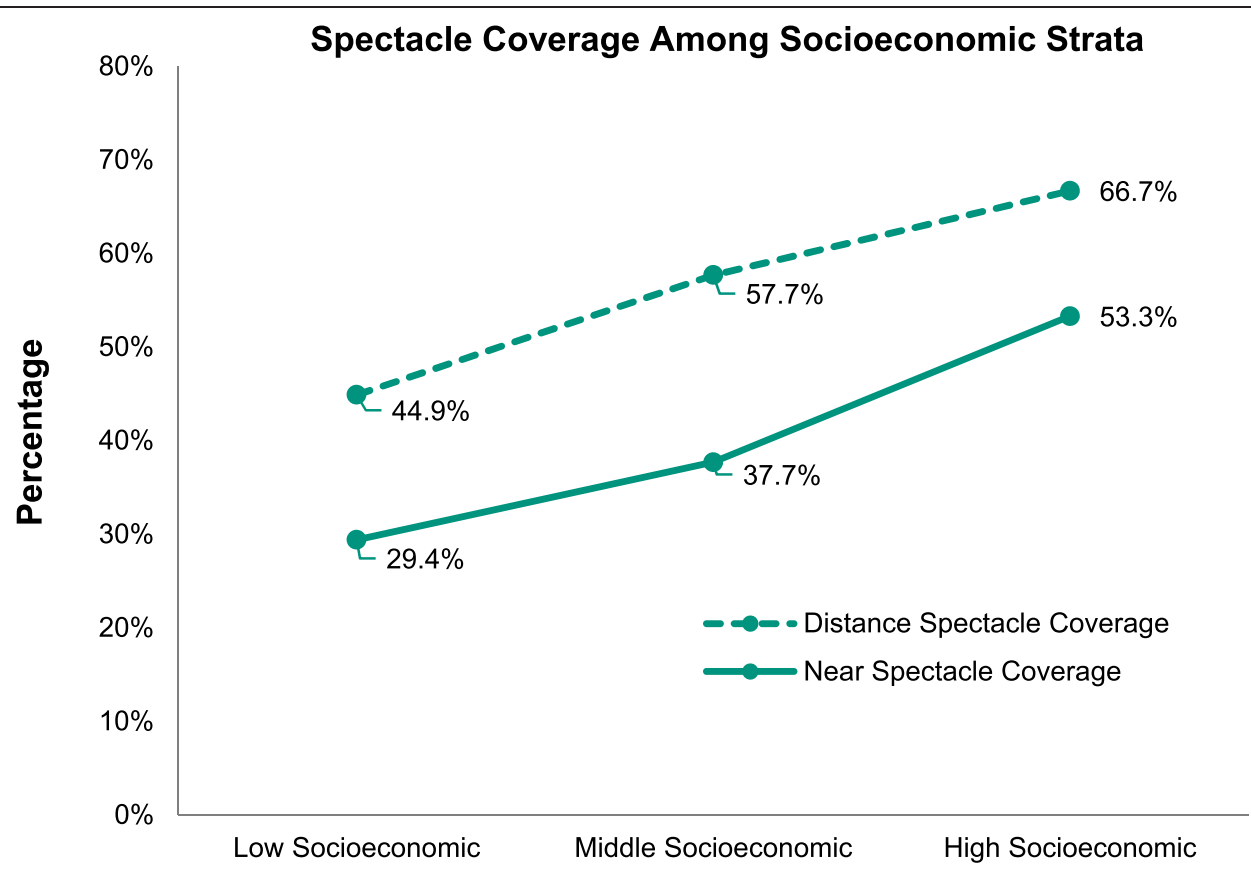

FIGURE 2. Spectacle coverage distribution by socioeconomic strata.

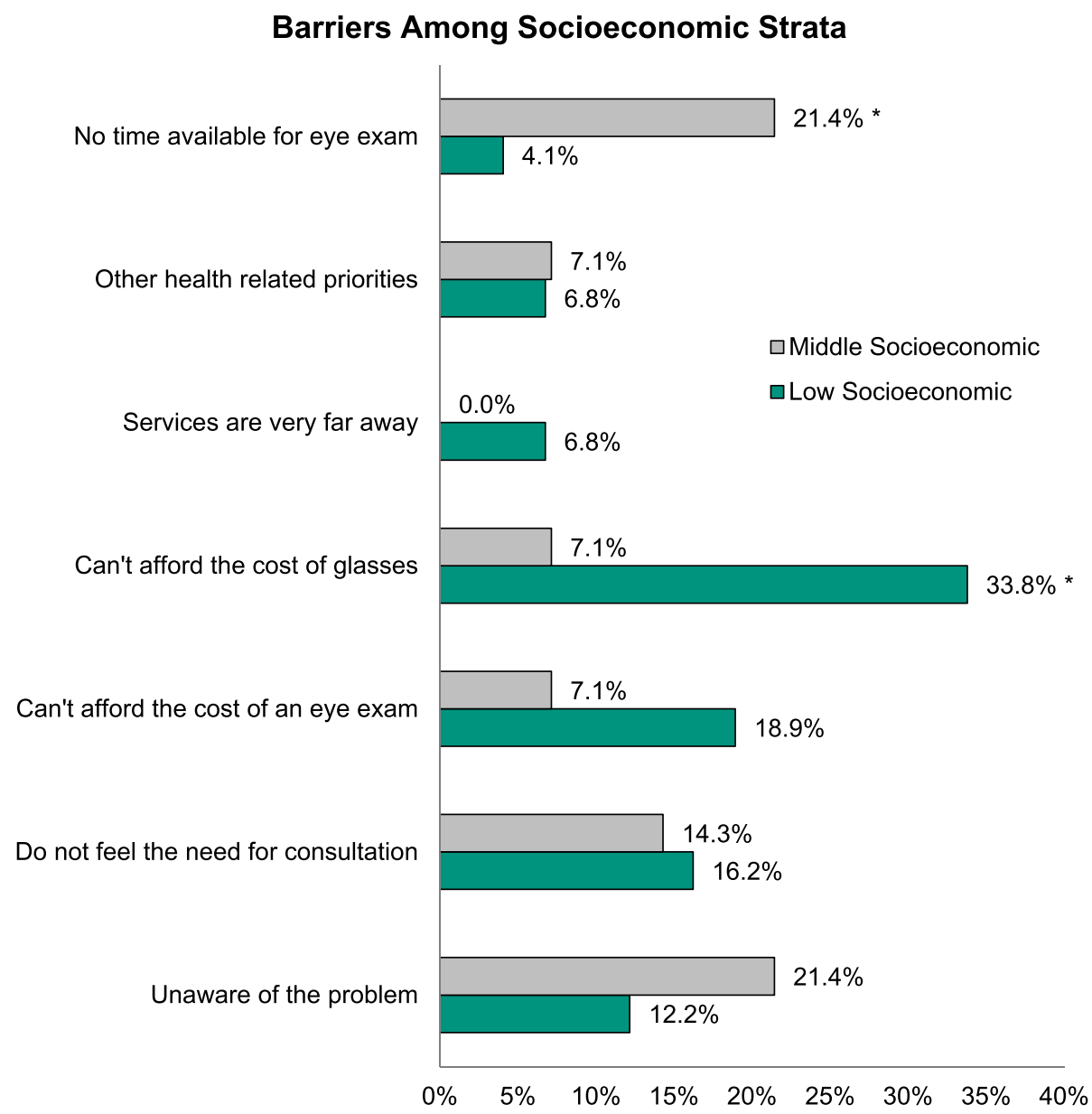

FIGURE 3. Barriers distribution by socioeconomic strata. ${ }^{*} P<.05$. 
the lowest socioeconomic strata, whereas the lowest visual impairment reported was that from Usaquen district, which belongs to the highest socioeconomic strata in the city. These data reflect the inequities of income distribution in the city because lowest income seems to influence access to eye care services, spectacle correction, and awareness of eye care conditions. The prevalence of visual impairment reported in this study is higher than visual impairment prevalence reported in other Rapid Assessment of Refractive Error studies. For instance, Uganda has a reported prevalence of $8.4 \%,{ }^{17}$ and Tanzania has $10.4 \%{ }^{5}$ However, in earlier studies, male participation was higher and median age was lower than those in the present study. 5,16,17 This higher visual impairment in Bogotá indicates that the Colombian population has other needs and visual characteristics that require further study to identify the precise causes of this seemingly higher prevalence. Prevalence of presbyopia showed to increase with age as expected; however, $7.2 \%$ of participants 80 years and older did not present with presbyopia. This could be due to other factors such as a physiological effect in which pupil size reduces with age, increasing depth of focus, and allowing to see smaller objects better. It could also be related to the use presbyopic intraocular lenses or the presence of aphakia.

Spectacle coverage in the capital city was high for both distance vision and presbyopia. This wide coverage is probably due to the existence of optometry as a profession in the country for more than 50 years, ${ }^{30}$ the existence of a health law (Law 100), and a plan of public health 2016 to 2020 in Colombia within which eye health is included in the list of noncommunicable diseases. This law mandates provision of health services for the population. Under this law, lenses are covered for any prescription in addition to a percentage of the frame. ${ }^{31}$ Spectacle coverage reported in this study is higher than that reported in other Rapid Assessment of Refractive Error studies such as Uganda, Tanzania, and Eritrea, where there were 5.96, 1.69 , and $22.2 \%$ coverage for distance vision and $0,0.42$, and $9.9 \%$ for presbyopia, respectively. ${ }^{5,16,17}$

Colombia has adequate human resources to manage the preventable causes of blindness such as cataract. ${ }^{20}$ However, in Colombia, the greater concentration of ophthalmologists and optometrists is found in main cities such as Bogotá, Medellin, Cali, and Barranquilla, which becomes a barrier when attempting to access the service in rural or remote areas. ${ }^{32,33}$ Access barriers are higher for people with a subsidized health plan under which they must first attend a general consultation and then be referred to an optometrist or ophthalmologist for an eye examination. ${ }^{34}$ This process may reduce the benefit of the service because several months can lapse before the consultation, affecting people's motivation and/or access to public services. Also, the system encumbers the patients with additional transportation costs due to multiple visits. ${ }^{35,36}$ The subsidized plan covers people who do not have the means to pay for their own social security, which could also mean that they do not have the necessary resources to attend a private consultation. $31,37,38$

The main barrier to spectacle uptake reported by the participants was that they cannot afford the full cost of the spectacles, a statement that was recorded most often in the low socioeconomic strata, reflecting a difference in economic priorities among participants. Also, the affordability of spectacles could be affected because the health system provides only a basic range of lenses but not the frames, which might discourage the purchase of the spectacles. There were no barriers reported from participants living in the high socioeconomic strata, confirming that the economic factor is crucial to eye care access, compared with those from low socioeconomic strata. Advocacy for increasing eye care education campaigns for the community could be one of the recommendations to the relevant bodies in Bogotá such as the Secretary and Ministry of Health. We recommend eye health promotion and prevention activities to improve the awareness of the population about the importance of seeking for early eye examinations.

\section{Limitations}

Bogotá, being the capital of Colombia, faces several challenges. Security issues are the main difficulty in surveying the population and obtaining cooperation to participate in a study such as the Rapid Assessment of Refractive Error. Lack of trust of the survey by potential participants and lack of compliance in attending the eye examination were the main factors that extended data collection up to 9 months. Five thousand people were enumerated, of whom 2114 refused to participate in the study, and 2886 were examined. Several strategies were implemented to overcome the limitations, such as informative flyers before the enumeration date, social media campaign to reach the community, and seeking cooperation of community leaders and mayor's office from Bogotá. The significant imbalance between men and women willing to participate is also a limitation of the study. Another limitation regarding the prevalence of presbyopia is the slight overestimation given that the protocol is rapid, uses visual acuity as a cutoff, and is measured from patients 35 years and older.

\section{CONCLUSIONS}

Prevalence of age- and sex-standardized uncorrected refractive error $(12.5 \%)$ identified in the present study is higher than the uncorrected refractive error prevalence reported in the Rapid Assessment of Refractive Error from other regions of the world such as South India (5.5\%) and Eritrea (6.4\%). Prevalence of presbyopia in Bogotá is high, as expected, owing to the distribution of the population by age. Spectacle coverage was $50.9 \%$ for distance vision, but more than half of people with presbyopia (66.1\%) did not have the spectacles they require. That the main barrier determined is related to the cost of the spectacles may also indicate different priorities in terms of health expenses afforded by the people examined in Bogotá.

In addition to informing the prevalence of refractive error in a capital city of Latin America, the information on the prevalence of uncorrected refractive error and presbyopia in Bogotá will help in making informed decisions about eye care service delivery by the Colombian Ministry of Health.

\section{ARTICLE INFORMATION}

Supplemental Digital Content: The Appendix, The Rapid Assessment of Refractive Error (RARE) questionnaire and recording form, is available at http://links.Imw.com/OPX/A407.
Submitted: August 13, 2018

Accepted: March 29, 2019

Funding/Support: Lions Clubs International Foundation (SF1867/UND).
Conflict of Interest Disclosure: None of the authors have reported a financial conflict of interest.

Author Contributions and Acknowledgments: Conceptualization: LCL, KN, VFC; Data Curation: TJN; Formal Analysis: KN, TJN, LR; Funding Acquisition: LCL; Investigation: LCL, KN, 
VFC, TJN, MM, LR; Methodology: LCL, KN, VFC, JCS, TJN, LR; Project Administration: LCL; Supervision: LCL, MM; Writing - Original Draft: LCL, LR; Writing - Review \& Editing: LCL, KN, VFC, JCS, TJN, FP, LR.

The authors would like to acknowledge Lions Clubs International Foundation for sponsoring this project through the Lions Sight First grant, the Secretary of Health of Bogotá, the Councilor's Office, the PanAmerican Health Organization, La Salle University, and Centro de Rehabilitación para Adultos Ciegos (CRAC) foundation for supporting the implementation of the field work. Special thanks to Optica Alemana and Volver Foundation for their permanent support and donations to our projects. Management was provided by Brien Holden Vision Institute Foundation.

\section{REFERENCES}

1. Resnikoff S, Pascolini D, Mariotti SP, et al. Global Magnitude of Visual Impairment Caused by Uncorrected Refractive Errors in 2004. Bull World Health Organ 2008;86:63-70.

2. Pascolini D, Mariotti S. Global Estimates of Visual Impairment: 2010. Br J Ophthalmol 2012;96:614-22.

3. Loughman J, Nxelem LL, Faria C, et al. Rapid Assesment of Refractive Error, Presbyopia and Visual Impairment and Associated Quality of Life in Nampula, Mozambique. J Vis Impair Blind 2015;1:199-212.

4. Bourne RR, Stevens GA, White RA, et al. Causes of Vision Loss Worldwide, 1990-2010: A Systematic Analysis. Lancet Glob Health 2013;1:e339-49.

5. Mashayo E, Chan V, Ramson P, et al. Prevalence of Refractive Error, Presbyopia and Spectacle Coverage in Kahama District, Tanzania: A Rapid Assessment of Refractive Error. Clin Exp Optom 2015;98:58-64.

6. Robinson B, Feng Y, Woods CA, et al. Prevalence of Visual Impairment and Uncorrected Refractive ErrorReport from a Canadian Urban Population-based Study. Ophthalmic Epidemiol 2013;20:123-30.

7. Dandona R, Dandona L. Socioeconomic Status and Blindness. Br J Ophthalmol 2001;85:1484-8.

8. Senjam SS, Vashist P, Gupta N, et al. Prevalence of Visual Impairment Due to Uncorrected Refractive Error: Results from Delhi-Rapid Assessment of Visual Impairment Study. Indian J Ophthalmol 2016;64:387-90.

9. Holden BA, Fricke TR, Ho SM, et al. Global Vision Impairment Due to Uncorrected Presbyopia. Arch Ophthalmol 2008;126:1731-9.

10. Kovai V, Krishnaiah S, Shamanna BR, et al. Barriers to Accessing Eye Care Services among Visually Impaired Populations in Rural Andhra Pradesh, South India. Indian J Ophthalmol 2007;55:365-71.

11. World Health Organization (WHO). World Conference on Social Determinants of Health Rio de Janeiro; 2011. Available at: http://www.who.int/sdhconference/
declaration/Rio_political_declaration.pdf?ua $=1$. Accessed November 8, 2017.

12. World Health Organization (WHO). Action Plan for the Prevention of Avoidable Blindness and $\mathrm{Vi}$ sual Impairment 2009-2013: ISBN 978924 $1500173 ; 2013$. Available at: http://www.who. int/blindness/ACTION_PLAN_WHA62-1-English. pdf. Accessed November 9, 2017.

13. Munoz B, West SK. Blindness and Visual Impairment in the Americas and the Caribbean. $\mathrm{Br} J$ Ophthalmol 2002;86:498-504.

14. Galvis V, Rey J, Rodríguez L, et al. Blindness Prevalence in Santander - Colombia Department. Med UNAB 2009;12:1-6.

15. Pan American Health Organization (PAHO). Plan of Action for the Prevention of Blindness and Visual Impairment; 66th Session of the Regional Committee of WHO for the Americas: CD53/11; 2014. Available at: https:// www.paho.org/hq/index.php?option=com_docman\&task= doc_download\&ltemid=\&gid=42684\&lang=es. Accessed December 12, 2017

16. Chan VF, Mebrahtu G, Ramson P, et al. Prevalence of Refractive Error and Spectacle Coverage in Zoba Ma'ekel Eritrea: A Rapid Assessment of Refractive Error. Ophthalmic Epidemiol 2013;20:131-7.

17. Nsubuga N, Ramson P, Govender P, et al. Uncorrected Refractive Errors, Presbyopia and Spectacle Coverage in Kamui District, Uganda. Afr Vis Eye Health 2016;75:1-6.

18. Leasher JL, Lansingh V, Flaxman S, et al. Prevalence and Causes of Vision Loss in Latin America and the Caribbean: 1990-2010. Br J Ophthalmol 2014;98:619-28.

19. Secretaria Distrital de Planeación. Knowing the Districts from Bogotá, Demographic, Physical and Socioconomics Aspects Diagnosis 2009; 2011. Available at: http://www.sdp.gov. $\mathrm{co} /$ sites/default/files/dice092-cartillaconociendolocalidades2009.pdf. Accessed December 11, 2017.

20. Brusi L, Argüello L, Alberdi A, et al. Health Report from the Countries That Make up the Ibero-American Epidemiological Network for Visual and Eye Health (REISVO), 2009 and 2010. Cien Tecno Sal Vis Ocu 2015;13:1-34

21. Furtado JM, Lansingh VC, Carter MJ, et al. Causes of Blindness and Visual Impairment in Latin America. Surv Ophthalmol 2012;57:149-77.

22. Peña F, Ramírez O. Prevalence of Blindness in Colombia. Population Study in an Urban Community. Rev Franja Ocular 2001;2:3-6.

23. Schellini SA, Durkin SR, Hoyama E, et al. Prevalence and Causes of Visual Impairment in a Brazilian Population: The Botucatu Eye Study. BMC Ophthalmol 2009;9:1-9.

24. Uribe JA, Swenor BK, Muñoz BE, et al. Uncorrected Refractive Error in a Latino Population: Proyecto Ver. Ophthalmology 2011;118:805-11.

25. Varma R, Wang MY, Ying Lai M, et al. The Prevalence and Risk Indicators of Uncorrected Refractive
Error and Unmet Refractive Need in Latinos: The LoS Angeles Latino Eye Study. Invest Ophthalmol Vis Sci 2009;49:5264-73

26. Limburg $H$, Barria von-Bischhoffshausen $F$, Gomez $P$, et al. Review of Recent Surveys on Blindness and Visual Impairment in Latin America. Br J Ophthalmol 2008; 92:315-9.

27. Ostadimoghaddam $\mathrm{H}$, Fotouhi $A$, Hashemi $H$, et al. Prevalence of the Refractive Errors by Age and Gender: The Mashhad Eye Study of Iran. Clin Experiment Ophthalmol 2011;39:743-51.

28. World Health Organization (WHO). Elimination of Avoidable Visual Disability Due to Refractive Errors: WHO/PBL/00.79; 2000. Available at: http://apps.who. int/iris/bitstream/handle/10665/67800/WHO PBL 00. 79. pdf? sequence $=1$ \&isAllowed=y. Accessed December 14, 2017.

29. Marmamula S, Keeffe JE, Raman U, et al. Population-based Cross-sectional Study of Barriers to Utilisation of Refraction Services in South India: Rapid Assessment of Refractive Errors (RARE) Study. BMJ Open 2011;1:1-5.

30. Jimenez J. Historical Review of the Optometry Faculty. Rev Univ Salle 2011;31:23-33.

31. Colombia Ministry of Health. Illness Promotion and Prevention in Public Health: ISBN: 978-958-98220-0-5; 2007. Available at: https://www.minsalud.gov.co/Documentos \%20y\%20Publicaciones/GUIAS\%20DE\%20ATENCION\% 20-TOMO\%2ODOS.pdf. Accessed December 15, 2017.

32. Social MP, (PARS), Javeriana PU, et al. Human Resources in Health in Colombia; Balance, Competency and Prospective, 2nd ed. Bogotá: Impresol Ediciones Ltda; 2007.

33. Suárez RL, Puerto GS, Rodríguez ML, et al. The Crisis of the Colombian Health System: An Approach from Legitimacy and Regulation. Rev Gerenc Polit Salud 2017;16:34-50.

34. Arrivillaga M, Aristizabal JC, Pérez M, et al. Health Services Access Survey for Colombian Households. Gac Sanit 2016;30:415-20.

35. Restrepo ZJ, Silva MC, Andrade RF, et al. Access to Health Services: Analysis of Barriers and Strategies in Medellin, Colombia. Rev Gerenc Polit Salud 2014;13: 242-65.

36. Orfa OM, Muñoz EP. Public Policy for Human Resource in Health in Colombia: Elements for Reflection. Avan Enferm 2013;31:113-25.

37. Mendoza MA, Ojeda VM, Zárate AA. Efficiency in the Quality of the Service of Health Promotion Entities from the Colombian Subsidized Regime. Hacia Prom Salud 2017;22:13-25.

38. Marmamula S, Keeffe J, Rao GN. Uncorrected Refractive Errors, Presbyopia and Spectacle Coverage: Results from a Rapid Assessment of Refractive Error Survey. Ophthalmic Epidemiol 2009;16:269-74. 